\title{
Asociación de polimorfismos genéticos de las razas Cebú y Romosinuano con el desarrollo muscular y peso vivo final
}

\section{Association of Genetic Polymorphism in Zebu and Romosinuano with Muscle Development and Final Live Weight}

Ricardo Camacho Quiroga

recamachoq@aol.com

\begin{abstract}
Resumen
Se desarrolló un estudio en el municipio de Montería (Córdoba, Colombia) para determinar el efecto que posee el polimorfismo de nucleótido simple del gen MYF5 del BTA5 sobre el peso vivo al sacrificio de una población de 57 animales de la raza Cebú Brahman y la raza criolla colombiana Romosinuano. Por medio de esta prueba se identificó que la variante alélica homocigota 11 no se encontraba segregada dentro de la población, siendo sólo identificados los alelos homocigotos 22 y el respectivo heterocigoto 12. Debido a que el peso vivo promedio al cual llegan los animales en Colombia a sacrificio es de $430 \mathrm{Kg}$, este grupo fue dividido en superiores e inferiores a dicho promedio. Los datos obtenidos fueron analizados a través de un modelo de regresión logística para variables binomiales. Los resultados demostraron que el alelo con mejor comportamiento fue el homocigoto en la raza romosinuano seguido del mismo alelo en la raza cebú, lo que demuestra que existe una asociación directa del polimorfismo homocigótico con una mejor respuesta sobre el peso vivo final al sacrificio del los animales. Por otra parte, se observó cómo las dos variables tienen un efecto sobre el peso al sacrificio, explicando su variación en un $70 \%$ aproximadamente.
\end{abstract}

Palabras clave: alelo, BTA5, heterocigoto, homocigoto, MYF-5, modelos lineales generalizados, polimorfismo.

\begin{abstract}
A study was undertaken in the municipality of Montería (Cordoba, Colombia) in order to determine the effect that has the single nucleotide polymorphism of MYF5 gene of BTA5 on live weight at slaughter of a population of 57 animals of Zebu
\end{abstract}

${ }^{\text {a} D o c e n t e ~ d e ~ G e n e ́ t i c a ~ y ~ M e j o r a m i e n t o ~ A n i m a l . ~ F a c u l t a d ~ d e ~ M e d i c i n a ~ V e t e r i n a r i a ~ y ~ Z o o t e c n i a . ~}$ Universidad de Ciencias Aplicadas y Ambientales (UDCA). 
Brahman and Romosinuano. Through this test it was found that the homozygous variant allele 11 was not segregated in the population being homozygous alleles identified only 22 and the respective heterozygotes 12 . Because the average live weight at which animals reach slaughter in Colombia is $430 \mathrm{Kg}$, this group was divided into above and below from that average. The data were analyzed using a logistic regression model for binomial data. The results showed that the best performing allele was homozygous in Romosinuano, followed by the same allele in Zebu, which shows that there is a direct association of the homozygous polymorphism with a better response on the final live weight of slaughter animals. On the other hand, it was observed that the two variables have an effect on slaughter weight.

Key words: Allele, BTA5, Generalized Linear Models, Heterozygous, Homozygous, MYF-5, Polymorphism.

\section{Introducción}

El crecimiento muscular es producido por un aumento en el diámetro y la longitud de las fibras. En contraste con muchos otros tejidos, el crecimiento muscular postnatal resulta principalmente de la hipertrofia de los músculos. Esta hipertrofia está caracterizada por el incremento en el tamaño de la fibra sin un incremento apreciable en el número de ellas, esto significa que el crecimiento muscular postnatal se debe a hipertrofia y no a hiperplasia. La hiperplasia de fibras musculares se observa en los animales que se conocen como de doble musculatura en los cuales hay un incremento en el número real de fibras musculares especialmente en los músculos superficiales de la espalda y región proximal de la extremidad posterior. Cuando dos animales de la misma especie, raza, sexo y alimentados de igual manera alcanzan tamaños corporales diferentes a una cierta edad, probablemente se debe a diferencias en el número de fibras musculares y no al tamaño de las fibras (Swatland 1991).

El factor genético está ligado al factor racial, ya que las razas de bovinos para carne que se conocen hoy en día, provienen de animales con características genéticas similares que se transmiten de generación en generación. De ahí que los animales de una misma condición racial tienen la tendencia a crecer de una manera típica que se puede apreciar por su composición corporal. Así, por ejemplo, los animales de razas lecheras tienden a depositar una mayor proporción de grasa interna que los de carne. Sin embargo, algunos grupos raciales como el Cebú pueden exhibir un patrón de crecimiento diferente, expresado bien sea por la velocidad como crecen los tejidos, o por el peso final que obtienen cuando alcanzan su madurez. La velocidad de crecimiento se conoce también como precocidad.

De igual manera, existen animales de madurez temprana y madurez tardía. La madurez no está estrictamente relacionada con la edad, sino con el peso adulto alcanzado. Esto significa que los animales de madurez temprana obtienen tamaños

corporales pequeños o pesos adultos inferiores que los animales de madurez tardía. 
La precocidad y la madurez pueden encontrarse combinadas dentro de los mismos animales; es decir, pueden existir animales de crecimiento rápido y pesos corporales altos.

Este tipo de animales, de crecimiento rápido y madurez tardía, tienden a ser más magros puesto que el mayor aumento de peso corporal está representado por la masa muscular. La acumulación de grasa, en particular la relacionada con los músculos, se forma posterior al desarrollo muscular. De otro lado, los animales que terminan su desarrollo muscular temprano, no solamente tienden a obtener pesos pequeños sino que también acumulan mayor proporción de grasa.

El ganado criollo Romosinuano debe su nombre a la carencia de cuernos (topo o romo) y a su lugar de origen y desarrollo, el valle del rió Sinú, en el departamento de Córdoba. Se le identifica como un ganado tipo carne, en cuyo estado adulto los machos pesan $550 \mathrm{~kg}$ y las hembras $430 \mathrm{~kg}$, mientras que en el momento del destete y a los 18 meses pesan 170 y $245 \mathrm{~kg}$ respectivamente. Es además la raza que presenta los intervalos entre partos más cortos. Así mismo, se ha demostrado que los productos F1 con Cebú Brahman superan al Cebú en peso a los 18 meses $(+3.8 \%$ ), dando como resultado una producción del $13.4 \%$ más de carne por cada 100 vacas apareadas y rendimientos en canal superiores al $56 \%$. El mejoramiento genético está orientado a obtener animales más pesados al destete, con un incremento hasta del $12 \%$ y de $15 \%$ para el año y medio de vida, al utilizar el Romosinuano en cruzamientos con Cebú, especialmente de tipo Brahman (Rodríguez et al. 1993).

En Colombia el Brahman es la principal raza cebuína existente en las regiones de clima medio y cálido, tanto en estado puro como en cruces, alcanzando un porcentaje muy alto entre las razas importadas. Se caracteriza por su rusticidad, adaptabilidad al medio, por su precocidad (excelente para cruzamientos comerciales), por su habilidad materna y su longevidad. El peso corporal para toros adultos fluctúa entre 800-1.100 Kg., el de los terneros al nacer esta entre 35-40 Kg. Los rendimientos netos son del orden de 58-63\% (Rodríguez et al. 1993). De la totalidad de la población ganadera del país, el $72 \%$ corresponde a razas índicas, el $15 \%$ a taurinas y el $13 \%$ a razas criollas colombianas.

En otra instancia, la genética es expresada por cierta habilidad que poseen los animales para disponer de los nutrientes, en lo que se conoce como eficiencia alimenticia. La eficiencia alimenticia se relaciona con la cantidad o proporción de alimento que es convertida en carne. Los animales de rápido crecimiento se caracterizan por tener una eficiencia alimenticia superior (Sánchez et al. 2002). Además del factor genético, el crecimiento muscular está influenciado por otros factores entre los que se cuentan: la especie, la raza, el sexo, la edad y la actividad física (Sánchez et al. 2002), y los factores ambientales (Soria \& Corva 2004).

Los genes específicos del músculo, como los genes MyoD, son conocidos por controlar la miogénesis. La variación genética en las hormonas, factores de crecimiento y proto-oncogenes puede diferencialmente controlar la expresión y actividad de los genes MyoD y una variedad de otros procesos no relacionados con desarrollo y metabolismo (TePas \& Visscher 1994). Si la variación dentro de un gen puede 
asociarse con la cantidad de carne, como por ejemplo, el crecimiento del músculo, entonces esta variación es utilizada como un marcador genético dentro de los programas de selección asistida por marcadores (TePas \& Visscher 1994).

Existen cuatro miembros de genes de la familia $\mathrm{MyoD}$ en vertebrados: Myf-3, Myf4 (Miogenin), Myf-5, Myf-6 (MRF-4, Herculin). Cada uno de los cuatro genes tiene un patrón distinto de expresión, el cual indica una función distinta para cada factor (Buckingham 1992). En estudios in vitro ellas se convierten en activas en la formación de dímeros complejos con proteínas de la ubicuidad expresada por el gen E2A el cual forma un complejo proteico MyoD-E2A, que está ligado a secuencias reguladoras de transcripción de genes específicos de músculo. De este modo activa la expresión de genes específicos de tejido y diferentes estados del desarrollo, tales como la actína, desmina, tropomiosina y titina (Buckingham 1992, TePas \& Visscher 1994). Las proteínas Inhibidoras de Diferenciación (ID), previenen la unión del complejo MyoD-E2A permitiendo que las células permanezcan en estado de crecimiento proliferativo. Cuando el ID disminuye se activa el complejo MyoD-E2A (Lodish \& Darnell 2005).

Mediante la técnica de polimorfismos de nucleótido simple (SNPs), se han detectado genes ubicados en el BTA5 asociados con características de crecimiento en bovinos como son el gen MYF5, homologo del Factor de Determinación Miogénico Humano en un 96 \% (Clark et al. 1990). Droguemuller y Kempers 2000 reportaron una mutación de A por G en la posición 1948 pb. en el intrón 2. Li y col., en el 2004 reportaron para esta misma región dos alelos: alelo "1" CAA y alelo "2" CGA con tres genotipos 11, 12, 22, observando mayores ganancias de peso en el genotipo 22 relacionado con ganancia diaria predestete y ganancia diaria total considerándolo como un gen candidato posicional para el desarrollo de este trabajo.

\section{Materiales y métodos}

Este trabajo fue llevado a cabo en el municipio de Montería, Córdoba (Colombia), en el frigorífico Frigosinu. La temperatura promedio es de $36^{\circ} \mathrm{C}$, con una humedad relativa del $90 \%$. Los animales eran provenientes del mismo sistema de producción, sometidos bajo el mismo rigor alimenticio, todos machos, castrados, llevados a sacrificio a la edad de 28 meses, pesados antes del sacrificio y después de un ayuno de 12 horas.

Se tomó una muestra de sangre de $50 \mathrm{ml}$ de cada individuo, para realizar la respectiva extracción de ADN e identificación del SNP correspondiente al gen MYF-5, por medio de la técnica de PCR-RFLP. Las secuencias de los primers usados en la amplificación de los fragmentos fueron las aportadas por las bases de datos del GeneBank.

Las muestras fueron centrifugadas a 6000 r.p.m, y el pellet obtenido se resuspendió en $500 \mathrm{ml}$ de una solución amortiguadora que contenía $\mathrm{NaCl}$, Tris $\mathrm{HCl}$ y EDTA (buffer STE). El sobrenadante fue descartado y se adicionaron $500 \mathrm{ml}$ de tampón de digestión, $22 \mathrm{ml}$ de DTT 0.1M y $27 \mathrm{ml}$ de proteinasa K $(20 \mathrm{mg} / \mathrm{ml})$. Esta mezcla 
se incubó durante tres horas a $56^{\circ} \mathrm{C}$, y se adicionaron $500 \mathrm{ml}$ de fenol, transfiriendo la fase acuosa a otro tubo eppendorf al cual se le agregaron $300 \mathrm{ml}$ de fenol y 300 $\mathrm{ml}$ de cloroformo para ser mezclados manualmente. Luego se centrifugó para volver a tomar la fase acuosa y transferirla a un vial conteniendo $700 \mathrm{ml}$ de cloroformo. Finalmente, a la fase acuosa se le adicionaron dos volúmenes de etanol absoluto y la mezcla fue colocada a $-20^{\circ} \mathrm{C}$ por 30 toda la noche con el fin de precipitar el ADN. Una vez precipitado, el ADN se centrifugó a 14000 r.p.m por 15 minutos y el pellet se sometió a dos baños con etanol al $70 \%$. Posteriormente el pellet se secó y se resuspendió en un tampón TE (Tris HCl, pH 8.0 y EDTA) y almacenó a $-20{ }^{\circ} \mathrm{C}$ (Sambrook et al. 1989).

Se realizó una primera PCR con los anteriores iniciadores denominados MYF5. Luego se realizó una segunda amplificación con el producto de PCR obtenido previamente (PCR anidada).

Los productos de PCR fueron digeridos usando la enzima TaqI, que corta la cadena de DNA en el sitio T/CGA incubando a $37 \mathrm{C}$ por 3 horas. Los fragmentos se visualizaron en un gel de agarosa al 1.5\% por electroforesis con un Buffer de $1 \mathrm{x}$ TBE y teñidos usando EZ-Vision $®$. El genotipo de cada animal se determinó basado en el número de fragmentos que se obtuvieron: alelo 1 no cortado y alelo 2 cortado.

\section{Análisis estadístico y discusión}

Para el análisis de los datos se usaron variables de tipo binomial, donde la variable dependiente fue el peso vivo de los animales al sacrificio medido en kilogramos. Teniendo en cuenta los datos aportados por el plan estratégico para la ganadería 2019 de la federación nacional de ganaderos, el promedio al que llegan los animales al sacrificio en Colombia es de $430 \mathrm{~kg}$; por esta razón, los animales cuyo peso fuera mayor a dicho valor se califican como "superior" (codificado como 1), mientras que los que estaban por debajo de este peso se calificaban como "inferior" (codificado como 0). Las variables independientes fueron la raza del animal tomándose CEBU como 0 y ROMO como 1; y MYF-5, que es el gen que codifica para el crecimiento muscular, donde el mejor alelo descrito anteriormente por diferentes grupos de investigación, es el homocigoto 22 , el cual fue codificado como 0 y el heterocigoto 12, que fue codificado como 0.

\subsection{Modelo propuesto}

Dado que la variable dependiente Peso es una variable binaria, fue necesario emplear las técnicas de regresión logística para el modelo. Fue usado el siguiente código en el programa estadístico $\mathrm{R}$ para el ajuste de la regresión logística:

M $<-g l m(P E S O \sim R A Z A+M Y F$, family=binomial)

$\operatorname{summary}(\mathrm{M})$ 


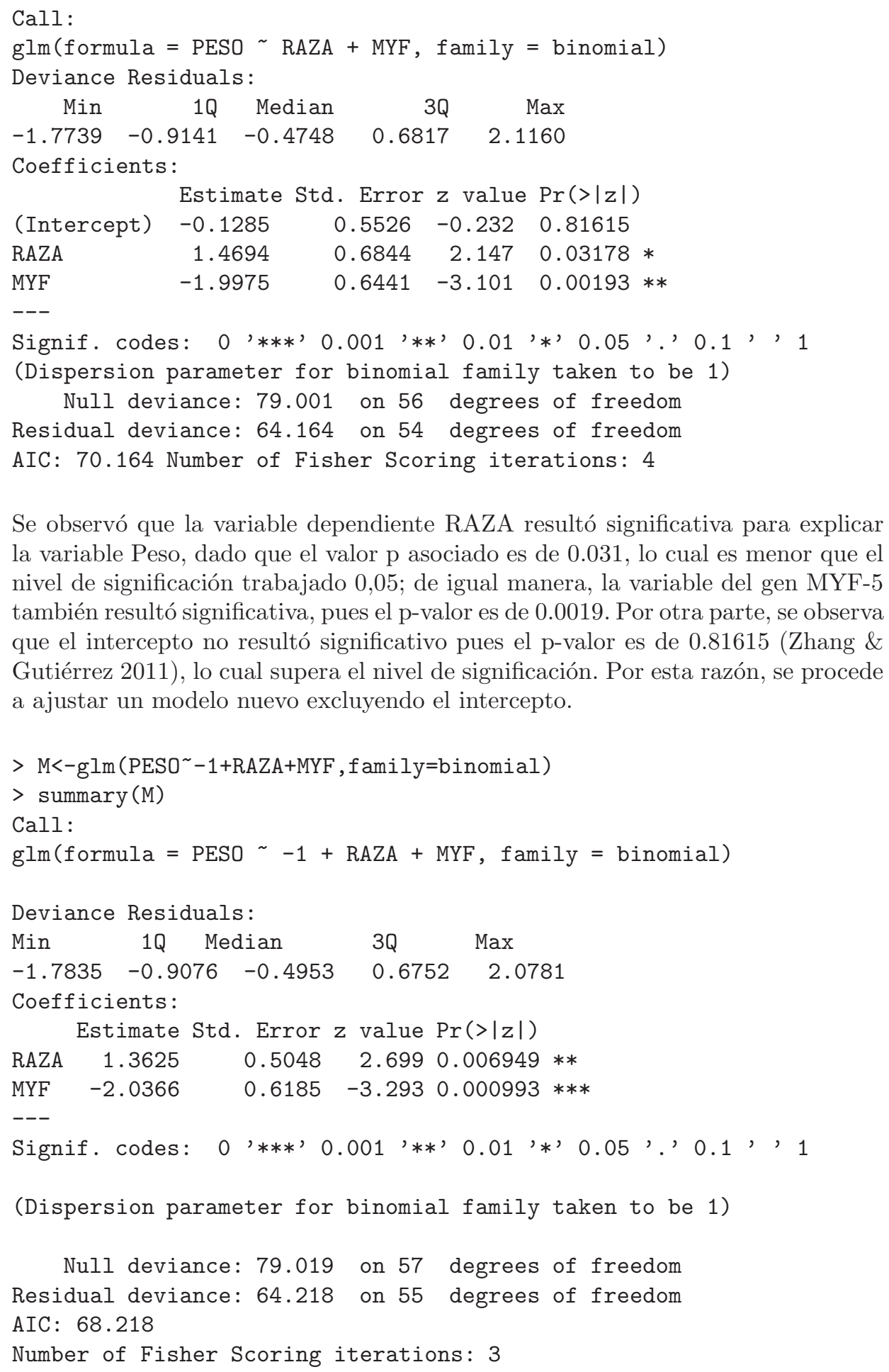

Se observó que la variable dependiente RAZA resultó significativa para explicar la variable Peso, dado que el valor p asociado es de 0.031, lo cual es menor que el nivel de significación trabajado 0,05; de igual manera, la variable del gen MYF-5 también resultó significativa, pues el p-valor es de 0.0019. Por otra parte, se observa que el intercepto no resultó significativo pues el p-valor es de 0.81615 (Zhang \& Gutiérrez 2011), lo cual supera el nivel de significación. Por esta razón, se procede a ajustar un modelo nuevo excluyendo el intercepto. 
De la anterior salida, se observa que las dos variables independientes siguen siendo significativas en el modelo, además que al tener en cuenta el criterio de Akaike AIC, se observa que dicho valor bajó de 70.164 al valor actual de 68.218 , es decir, este nuevo modelo se acerca más al modelo verdadero, lo cual justifica la exclusión del intercepto.

También se computó el valor del estadístico Wald, para comprobar la significación de los parámetros estimados.

1. Para la variable RAZA, el valor de Wald es $2.6992=7.284$, lo cual es menor que el percentil de $95 \%$ de una distribución chi-cuadrado con un grado de libertad 3.8414, entonces se concluye que el parámetro asociado con la variable RAZA es estadísticamente diferente de cero, justificando así la inclusión de la variable RAZA.

2. Para la variable MYF-5, el valor de Wald es $(-3.293) 2=10.8439$, lo cual es menor que el percentil $95 \%$ de una distribución chi-cuadrado con un grado de libertad: 3.8414, entonces se concluye que el parámetro asociado con MYF5 es estadísticamente diferente de cero, justificando así la inclusión de la variable MYF-5 en el modelo.

\subsection{Estimación del modelo}

La interpretación de los parámetros estimados es llevada a cabo de la siguiente manera:

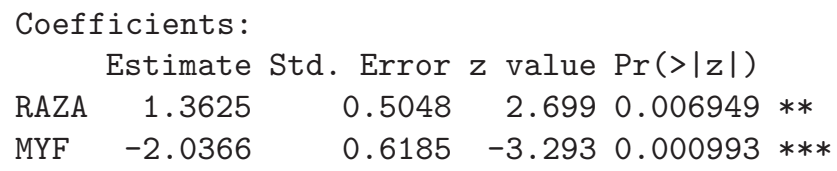

Así se llegó a corroborar los datos de la revisión bibliográfica donde se afirma que animales de la raza Romosinuano homocigotos para el gen MYF-5 poseen mejores pesos al sacrificio que los animales Cebú homocigotos y también se observó que el grupo de animales de menor peso eran los heterocigotos de la raza Cebú. De donde se concluye que este tipo de marcador molecular se encuentra asociado estrechamente con la presentación de la característica, de forma independiente a la raza.

\subsection{Validación del modelo}

En primer lugar probamos la hipótesis de que el modelo ajustado es correcto utilizando la estadística chi-cuadrado de Pearson de la siguiente manera:

$$
\chi^{2}=\sum_{i} \frac{\left(y_{i}-n_{i} \hat{\pi}_{i}\right)^{2}}{n_{i} \pi_{i}\left(1-\pi_{i}\right)}
$$


Donde $y_{i}$ es el número de animales con mayor peso dentro de cada una de las cuatro combinaciones de RAZA y MYF-5 y $n_{i}$ es el número total de animales que fueron pesados en cada una de las cuatro combinaciones. Estos valores se presentan en la Tabla 1.

\begin{tabular}{|c|c|c|c|c|}
\hline RAZA & 0 & 0 & 1 & 1 \\
\hline MYF-5 & $n_{i}$ & $y_{i}$ & $n_{i}$ & $y_{i}$ \\
\hline 0 & 11 & 4 & 20 & 17 \\
1 & 8 & 2 & 18 & 5 \\
\hline
\end{tabular}

Tabla 1: Tabulación cruzada del modelo logístico

\section{Conclusiones}

Estos tipos de análisis son muy informativos debido a que muchas características evaluadas dentro de programas de mejoramiento animal están inclinadas a observaciones directas sobre el fenotipo tomando como base la deferencia racial, pero no exploran las herramientas de la selección basada en marcadores moleculares como fue este el caso. Hasta el momento se ha explorado la causa por la cual dos animales, sin diferencia racial sometidos bajo condiciones similares, expresan rasgos productivos y zootécnicos diferentes.

Conociendo que el alelo homocigoto del gen MYF-5 es un marcador identificado para crecimiento y desarrollo muscular, el cual se observó que tuvo un buen desempeño durante la prueba. Se deben seguir programas orientados a identificar poblaciones de progenies con dicho alelo para así poder preservar esas características positivas que este confiere. Adicionalmente se recomendaría llevar a cabo futuras pruebas de cuantificación de aporte al peso con cada una de las dos variables de influencia, sabiendo que estas explican en un $70 \%$ la respuesta de este trabajo.

No es nuevo el conocimiento sobre el mejor desempeño que poseen ciertas razas sobre el ganado cebuino, pero qué mejor que poder encontrar razas de tipo criollo que poseen la rusticidad de las índicas pero con un componente productivo mayor. Por medio de estos resultados se abre un panorama más claro sobre el por qué usar razas de mayor precocidad, no sólo por ser posibles codificantes de un marcador molecular, sino también porque generan mayores aportes sobre el peso final al cual son llevadas a sacrificio, no siendo atrevido afirmar que inclusive dentro de animales heterocigotos que no poseen el mejor desempeño, podrían superar a la raza Brahman de manera independiente. Para esto sería importante estimar los aportes individuales de cada una de las variables de forma separada.

Recibido: 6 de diciembre de 2010 Aceptado: 9 de marzo de 2011 


\section{Referencias}

Buckingham, M. (1992), 'Making Muscles in Mammals', Trends Genetics 8, 144 148.

Clark, L., Armstrong, C., Knox, K. \& Mayrose, V. (1990), 'The Effect of Allin/AII-Out Management on Pigs From a Herd With Enzootic Pneumonia', Veterinary Medicine 86, 946 - 951.

Lodish \& Darnell (2005), Biología Celular y Molecular, Panamericana Editorial.

Rodríguez, C., Galina, C. S., Gutiérrez, C., Navarro, R. \& Piccinall, I. R. (1993), 'Evaluación de la actividad sexual de los toros cebu bajo condiciones de empadre múltiple con hembras sincronizadas con pgf2a', Ciencias Veterinarias 15, $41-49$.

Sambrook, J., Fritsch, E. F. \& Maniatis, T. (1989), Molecular Cloning: A Laboratory Manual, Cold Spring Harbor.

Sánchez, A. O., Ganchou, F. P., Arámbulo, R. C., Martínez, G. P. \& Belloso, E. S. (2002), 'Evaluación ultrasonográfica del crecimiento del folículo ovulatorio en vacas anéstricas mestizas cebú post-tratamiento con norgestomet y ecg', Archivos Latinoamericanos de Producción Animal 10, 20 - 23.

Soria, L. \& Corva, P. M. (2004), 'Factores genéticos y ambientales que determinan la terneza de la carne bovina', Archivos Latinoamericanos de Producción Animal 12, 73 - 88 .

Swatland, H. J. (1991), Estructuras y desarrollo de los animales de abasto, Editorial Acribia.

TePas, M. F. W. \& Visscher, A. H. (1994), 'Genetic Regulation of Meat Production by Embryonic Muscle Formation: a Review', Journal of Animal Breed Genetics 111, $404-412$.

Zhang, H. \& Gutiérrez, H. A. (2011), Teoría estadística: aplicaciones y métodos, Universidad Santo Tomás. 